\title{
The JAK1/2 Inhibitor Ruxolitinib Reverses Interleukin-6-Mediated Suppression of Drug-Detoxifying Proteins in Cultured Human Hepatocytes ${ }^{\mathrm{S}}$
}

\author{
Marie Febvre-James, Arnaud Bruyère, Marc Le Vée, and Olivier Fardel
}

Institut de Recherches en Santé, Environnement et Travail (IRSET), UMR INSERM U1085, Faculté de Pharmacie, Université de Rennes 1, Rennes, France (M.F.-J., A.B., M.L.V., O.F.) and Pôle Biologie, Centre Hospitalier Universitaire, Rennes, France (O.F.)

Received August 11, 2017; accepted November 17, 2017

\begin{abstract}
The inflammatory cytokine interleukin (IL)-6, which basically activates the Janus kinase (JAK)/ signal transducer and activator of transcription (STAT) signaling pathway, is well known to repress expression of hepatic cytochromes P-450 (P450s) and transporters. Therapeutic proteins, like monoclonal antibodies targeting IL-6 or its receptor, have consequently been demonstrated to restore full hepatic detoxification capacity, which results in inflammatory disease-related drug-drug interactions (idDDIs). In the present study, we investigated whether ruxolitinib, a small drug acting as a JAK1/2 inhibitor and currently used in the treatment of myeloproliferative neoplasms, may also counteract the repressing effects of IL- 6 toward hepatic detoxifying systems. Ruxolitinib was found to fully inhibit IL-6-mediated repression of P450 (CYP1A2, CYP2B6, and CYP3A4) and transporter (NTCP, OATP1B1, and OCT1) mRNA levels in primary human hepatocytes and differentiated hepatoma HepaRG cells.
\end{abstract}

Such effects were dose-dependent, with ruxolitinib $\mathrm{EC}_{50}$ values around 1.0-1.2 $\mu \mathrm{M}$ and thus close to ruxolitinib plasma levels that can be reached in patients. Moreover, they were associated with concomitant restoration of $\mathrm{P450}$ and drug transporter activities in IL-6-exposed HepaRG cells. By contrast, ruxolitinib failed to suppress the repression of drug-detoxifying protein mRNA levels caused by IL-1 $\beta$. The JAK inhibitor and anti-rheumatoid arthritis compound tofacitinib was additionally found to reverse IL-6mediated suppression of P450 and transporter mRNA expressions. Taken together, our results demonstrated that small drugs acting as JAK inhibitors, like ruxolitinib, counteract IL-6-mediated repression of drug-metabolizing enzymes and drug transporters in cultured human hepatocytes. These JAK inhibitors may consequently be hypothesized to restore hepatic detoxification capacity for patients suffering from inflammatory diseases, which may in turn cause idDDls.
Introduction

Drug-mediated alteration of drug detoxification path ways is a major cause of drug-drug interactions (DDIs) (Cascorbi, 2012). Such pharmacokinetics-related DDIs usually involve a small-molecule drug, i.e., the perpetrator, which directly inhibits activity of drugmetabolizing enzymes or drug transporters or regulates their expression. This will then result in decreased or enhanced clearance of a coadministrated drug, i.e., the victim, substrate for these detoxifying proteins. These DDIs therefore implicate small-drug perpetrators mostly acting as inhibitors of drug-metabolizing cytochrome P-450 (P450) or drug transporter activity, through competitive or noncompetitive mechanisms, or as inducers of drug-metabolizing enzyme expression. Numerous clinical examples of such DDIs have been reported in the literature (Danton et al., 2013). The possibility that a new

This work was supported by Cancéropole Grand Ouest (Project HII-GO) and the Ligue contre le Cancer (Comité d'llle et Vilaine et Comité de Vendée).

https://doi.org/10.1124/dmd.117.078048.

S This article has supplemental material available at dmd.aspetjournals.org. molecular entity may be the perpetrator or the victim of a putative DDI must by regulation be investigated by pharmaceutical companies during preclinical drug development (Prueksaritanont et al., 2013).

The increase in the clinical use of therapeutic proteins (TPs) has recently drawn attention to the potential DDIs between TPs and smallmolecule drugs (Evers et al., 2013). Indeed, inflammatory cytokines such as interleukin (IL)- $1 \beta$, IL-6, and tumor necrosis factor- $\alpha$ are potent repressors of hepatic cytochrome P-450 and drug transporter expression (Morgan et al., 2008; Fardel and Le Vee, 2009), which is known to commonly lead to reduced clearance of drugs in patients suffering from infectious and/or inflammatory diseases (Morgan, 2009). The use of TPs acting as anticytokine drugs, like monoclonal antibodies (mAbs) directed against circulating inflammatory cytokines or cytokine receptors, has consequently been hypothesized to neutralize the repressing effects of inflammatory cytokines toward drug-detoxifying protein expression; in this way, it probably restores full hepatic drugdetoxification capacity for patients suffering from inflammatory or infectious diseases. This may be the source of DDIs (Harvey and Morgan, 2014), which may in fact be considered as inflammatory disease-related DDIs (idDDIs). This hypothesis has been validated for

ABBREVIATIONS: BSP, bromosulfophthalein; CRP, C-reactive protein; P450, cytochrome P-450; DDI, drug-drug interaction; DMSO, dimethyl sulfoxide; $\mathrm{EC}_{50}$, half-maximal effective concentration; $\mathrm{E} 3 \mathrm{~S}$, estrone-3-sulfate; FBS, fetal bovine serum; idDDI, inflammatory disease-related drugdrug interaction; IL, interleukin; JAK, Janus kinase; LC-MS/MS, liquid chromatography coupled to tandem mass spectrometry; mAb, monoclonal antibody; NTCP, sodium-taurocholate cotransporting polypeptide; OATP, organic anion-transporting polypeptide; OCT, organic cation transporter; PBS, phosphate-buffered saline; STAT, signal transducer and activator of transcription; TEA, tetra-ethylammonium; TP, therapeutic protein. 
TPs targeting the IL-6 pathway in patients with rheumatoid arthritis. Indeed, the mAbs tocilizumab and sarilumab, directed against the IL-6 receptor $\alpha$, as well as the IL-6-neutralizing mAb sirukumab, reduce exposure of coadministrated drugs like simvastatin, midazolam, or omeprazole (Schmitt et al., 2011; Zhuang et al., 2015; Lee et al., 2017), most probably through reversal of IL-6-mediated suppression of P450 expression (Jiang et al., 2016).

Ruxolitinib (also known as INCB018424) is a small drug belonging to the emerging class of Janus kinase (JAK) inhibitors and currently used clinically in the treatment of JAK2 $V 617 F$-positive myeloproliferative neoplasms, including intermediate or high-risk myelofibrosis and polycythemia vera (Bose and Verstovsek, 2017). Besides the JAK2 isoform, primarily associated with receptors for the hematopoietic growth factors erythropoietin and thrombopoietin, the JAK1 isoform, which plays a major role in the signaling pathway of inflammatory cytokines, is also potently inhibited by ruxolitinib. With respect to the two other members of the JAK family, tyrosine kinase 2 (TYK2) is additionally targeted by ruxolitinib, whereas JAK3 is less sensitive (Quintas-Cardama et al., 2010). Ruxolitinib is nevertheless considered as belonging to the class of first generation pan-JAK inhibitors (Baker and Isaacs, 2017).

JAK1, JAK2, and TYK2 are thought to play a key role in IL-6 signaling pathway. Indeed, these JAK isoforms are activated/phosphorylated upon IL-6 binding to its receptor and downstream they phosphorylate signal transducer and activators of transcription (STAT) 1 and 3, which triggers molecular genomic response to IL-6 (Hunter and Jones, 2015). It is then probable that ruxolitinib may antagonize most IL-6 effects, which probably contributes to its well reported anti-inflammatory properties. In this context, it may be hypothesized that ruxolitinib may counteract the suppressing effects of IL-6 toward drug-detoxifying proteins, as reported above for TPs targeting the IL-6 pathway. The present study was therefore designed to investigate this hypothesis, using primary human hepatocytes and highly differentiated hepatoma HepaRG cells, which are recognized as convenient cell systems to study cytokine effects toward hepatic detoxifying enzymes and transporters (Aitken and Morgan, 2007; Le Vee et al., 2009; Klein et al., 2015; Rubin et al., 2015). Our data demonstrate that ruxolitinib can effectively reverse the repressing effects of IL-6 toward P450s and drug transporters in vitro, suggesting that putative idDDIs with drugs handled by IL-6-targeted-detoxifying proteins and coadministrated with ruxolitinib may have to be considered.

\section{Materials and Methods}

Chemicals and Reagents. Ruxolitinib and tofacitinib were provided by Selleckchem (Houston, TX). Verapamil, midazolam and bromosulfophthalein (BSP) were from Sigma-Aldrich (Saint-Quentin Fallavier, France). Phenacetine, acetaminophen, bupropion, and hydroxybupropion were purchased from Santa Cruz Biotechnology (Dallas, TX), whereas 1'-hydroxy-midazolam was provided by Toronto Research Chemicals (Toronto, Canada). $\left[{ }^{3} \mathrm{H}(\mathrm{G})\right]$ taurocholic acid (specific activity $5 \mathrm{Ci} / \mathrm{mmol}$ ), $\left[6,7-{ }^{3} \mathrm{H}(\mathrm{N})\right]$ estrone-3-sulfate (E3S) (specific activity $51.8 \mathrm{Ci} / \mathrm{mmol}$ ) and $\left[1-{ }^{14} \mathrm{C}\right]$ tetra-ethylammonium (TEA) (specific activity $3.5 \mathrm{Ci} / \mathrm{mmol}$ ) were purchased by Perkin-Elmer (Courtaboeuf, France). Recombinant human IL- 6 and IL-1 $\beta$ were supplied by R\&D Systems (Minneapolis, MN). All other chemicals and reagents were commercial products of the highest purity available. Stock solutions of ruxolitinib were prepared in dimethyl sulfoxide (DMSO), whereas those of IL-6 were done in sterile distilled water containing $0.1 \%$ bovine serum albumin. Control cultures received the same dose of solvents as treated counterparts.

Cell Culture. Primary human hepatocytes were obtained from adult donors undergoing hepatic resection for secondary tumors, via the Centre de Ressources Biologiques (CRB) Santé of Rennes BB-0033-0005 (University Hospital, Rennes, France), which has obtained the authorization no. DC-2008-630 from the French Ministry of Health to collect hepatic resections from the digestive surgery department and then to isolate and deliver the hepatocytes used in this study. Human hepatocytes, initially prepared by enzymatic dissociation of histologically normal liver fragments (Fardel et al., 1993), were seeded in 24 -well or 48 -well plastic plates at a density of $2 \times 10^{5} \mathrm{cells} / \mathrm{cm}^{2}$ in Williams' E medium (Invitrogen, Cergy-Pontoise, France), supplemented with 10\% (vol/vol) fetal bovine serum (FBS) (Perbio Sciences, Brébieres, France), $5 \mu \mathrm{g} / \mathrm{ml}$ bovine insulin (Sigma-Aldrich), $100 \mathrm{IU} / \mathrm{ml}$ penicillin, $100 \mu \mathrm{g} / \mathrm{ml}$ streptomycin, and $2 \mathrm{mM}$ glutamine (Invitrogen/Thermo Fisher Scientific, Waltham, MA). After 24 hours, this seeding medium was discarded, and primary hepatocytes were routinely cultured in Williams' E medium defined above and supplemented with $5 \times 10^{-5} \mathrm{M}$ hydrocortisone hemisuccinate (Upjohn, Paris La Défense, France) and 2\% (vol/vol) DMSO, as reported previously (Le Vee et al., 2009). All experimental procedures complied with French laws and regulations and were approved by the National Ethics Committee. Characteristics of hepatocyte donors are indicated in Supplemental Table 1.

Highly differentiated human hepatoma HepaRG cells were cultured as previously described (Le Vee et al., 2013). Briefly, cells plated in 24-well plates were first grown in Williams' E medium supplemented with $10 \%$ (vol/vol) FBS, $100 \mathrm{IU} / \mathrm{ml}$ penicillin, $100 \mu \mathrm{g} / \mathrm{ml}$ streptomycin, $5 \mu \mathrm{g} / \mathrm{ml}$ insulin, $2 \mathrm{mM}$ glutamine, and $5 \times 10^{-5} \mathrm{M}$ hydrocortisone hemisuccinate for 2 weeks. Cells were next cultured for an additional 2 weeks in the same medium supplemented with $2 \%$ (vol/vol) DMSO to get a full differentiation of the cells (Gripon et al., 2002). HepaRG cells were used for experiments as surrogates for human hepatocytes, notably for P450 activities and drug transport assays, owing to the cost of human hepatocytes and the well established convenience of using a cell line like HepaRG.

Reverse Transcription-Quantitative Polymerase Chain Reaction Experiments. Total RNAs were extracted using the TRI Reagent (Sigma-Aldrich). RNAs were then reverse transcribed using the Applied Biosystems cDNA Reverse Transcription kit (Thermo Fisher Scientific). PCR were next performed using the fluorescent dye SYBR Green methodology and a CFX384 real-time PCR system (Bio-Rad, Hercules, CA), as described already (Le Vee et al., 2009). Gene-specific primers for drug transporters, CYP2B6 and CYP3A4, C-reactive protein (CRP), IL-8, and 18S rRNA were exactly as previously reported (Jigorel et al., 2006; Le Vee et al., 2008). Other primers were CYP1A2 sense, CACTATCAGGACTTTGACAAG, and CYP1A2 antisense, AGGTTGACAATCTTCTCCTG. The specificity of each gene amplification was verified at the end of quantitative PCR reactions through analysis of dissociation curves of the PCR products. Amplification curves were analyzed with CFX Manager software (Bio-Rad), using the comparative cycle threshold method. Relative quantification of the steadystate target mRNA levels was calculated after normalization of the total amount of cDNA tested to the 18S rRNA endogenous reference, using the $2^{(-\Delta \Delta \mathrm{Ct})}$ method. Data were finally commonly expressed comparatively to mRNA expression found in untreated control cells, arbitrarily set at $1 \mathrm{U}$ for each analyzed gene.

Cytochrome P450 Activities. CYP3A4, CYP2B6, and CYP1A2 activities were measured by analyzing oxidation of specific substrates, i.e., midazolam, bupropion, and phenacetine for CYP3A4, CYP2B6, and CYP1A2, respectively, using liquid chromatography coupled to tandem mass spectrometry (LCMS/MS). Briefly, hepatocytes were exposed to $50 \mu \mathrm{M}$ midazolam, $100 \mu \mathrm{M}$ bupropion, or $200 \mu \mathrm{M}$ phenacetine for 4 hours in minimum essential medium, in the absence of FBS. Production of P450 activity-related metabolites, i.e., 1'-hydroxy-midazolam, hydroxybupropion, and acetaminophen, was then analyzed in culture supernatants through LC-MS/MS, using a high-performance liquid chromatography Aria system (Agilent, Les Ulis, France), equipped with a Kromasyl C18 $(4.6 \times 150 \mathrm{~mm})$ column (Interchim, Montluçon, France) and coupled to a tandem mass spectrometry TSQ Quantum Ultra (Thermo Fisher Scientific, Villebon sur Yvette, France) fitted with an electrospray ionization source (ESI+). Monitored ion transitions were at $342.0>168.0 \mathrm{~m} / \mathrm{z}$ for $1^{\prime}$-hydroxymidazolam, $152.0>110.0 \mathrm{~m} / \mathrm{z}$ for acetaminophen, and $256.1>$ $237.9 \mathrm{~m} / \mathrm{z}$ for hydroxybupropion. Amounts of produced metabolites were finally normalized to total protein cell content, determined by Bradford's method (Bradford, 1976).

Drug Transport Assays. Activities of the sinusoidal transporters sodiumtaurocholate cotransporting polypeptide (NTCP/SLC10A1), organic aniontransporting polypeptides (OATPs/SLCOS), and organic cation transporter 1 (OCT1/SLC22Al) were determined by measuring inhibitor-sensitive 
accumulation of reference substrates, as previously described (Jigorel et al., 2005). In brief, HepaRG cells were incubated for 5 minutes at $37^{\circ} \mathrm{C}$ with radiolabeled substrates, i.e., $30 \mu \mathrm{M}$ TEA (substrate for OCT1), $4 \mathrm{nM}$ E3S (substrate for OATPs), or $40 \mathrm{nM}$ taurocholate (substrate for NTCP), in the absence or presence of reference transporter inhibitors, i.e., $50 \mu \mathrm{M}$ verapamil (OCT1 inhibitor) or $100 \mu \mathrm{M}$ BSP (OATP inhibitor), or in the presence or absence of sodium (for NTCP activity) (Le Vee et al., 2013). The transport buffer used for assays consisted of $5.3 \mathrm{mM} \mathrm{KCl}, 1.1 \mathrm{mM} \mathrm{KH}_{2} \mathrm{PO}_{4}, 0.8 \mathrm{mM} \mathrm{MgSO}{ }_{4}, 1.8 \mathrm{mM}$ $\mathrm{CaCl}_{2}, 11 \mathrm{mM}$ D-glucose, $10 \mathrm{mM}$ HEPES, and $136 \mathrm{mM} \mathrm{NaCl}$, adjusted to $\mathrm{pH}$ 7.4; $\mathrm{NaCl}$ was replaced by $\mathrm{N}$-methylglucamine for transport assays in the absence of sodium. Cells were then washed twice in phosphate-buffered saline (PBS) and subjected to lysis in distilled water. Accumulation of radiolabeled substrates was next determined through scintillation counting of cell lysates and normalized to protein content, determined by Bradford's method. TEA uptake in the absence of verapamil minus uptake in the presence of verapamil, E3S uptake in the absence of BSP minus uptake in the presence of BSP, and taurocholate accumulation in the presence of sodium minus accumulation in the absence of sodium are thought to correspond to OCT1, OATP, and NTCP activities, respectively (Jigorel et al., 2005).

Immunocytochemistry. HepaRG cells were fixed with a cold solution of acetone for 10 minutes on ice. Cells were then washed with PBS and further incubated in PBS containing 4\% bovine serum albumin for 1 hour at room temperature. Cells were next incubated overnight with primary antibody against phosphorylated-STAT1 (Ozyme, Saint-Quentin-en-Yvelines, France). After two washes with PBS, the primary antibody was detected with anti-rabbit IgG coupled to Alexa Fluor (Cell Signaling Technology, Leiden, The Netherlands), whereas nuclei were stained by $4^{\prime}, 6$-diamidino-2-phenylindole for 1 hour at room temperature. Finally, immunofluorescence images were acquired with a confocal fluorescence microscope LEICA DMI 6000 CS (Leica Microsystemes SAS, Nanterre, France).

Calculation and Statistical Analysis. Quantitative data were routinely expressed as means \pm S.E.M. of at least three independent assays, each being performed in duplicate or triplicate. They were statistically analyzed using analysis of variance followed by the Newman-Keuls post-hoc test. The criterion of significance was $P<0.05$. Half-maximal effective concentration $\left(\mathrm{EC}_{50}\right)$ values of ruxolitinib toward cytokine mRNA expression were determined using GraphPad Prism 5.0 software (GraphPad Software, La Jolla, CA), through nonlinear regression on the basis of the four-parameter logistic function. Percentages of reduction in mRNA expression or activity of detoxifying proteins in response to IL- 6 or IL- $1 \beta$ treatment were calculated using the eq. (1):

$$
\begin{aligned}
\% \text { Reduction (mRNA expression or activity })= & 100-(\text { Value Cytokine } \\
& \times 100 / \text { Value Control })
\end{aligned}
$$

where Value Cytokine corresponds to mRNA level or P450 or transporter activity in cells exposed to cytokine (IL-6 or IL- $1 \beta$ ) and Value Control corresponds to mRNA level or P450 or transporter activity found in control untreated cells.

\section{Results}

Inhibition of IL-6-Induced CRP mRNA by Ruxolitinib in Primary Human Hepatocytes and HepaRG Cells. The responsiveness of primary human hepatocytes and HepaRG cells to IL-6 and ruxolitinib were determined first. To do so, cells were exposed for 24 hours to $10 \mathrm{ng} / \mathrm{ml} \mathrm{IL-6,} \mathrm{a} \mathrm{concentration} \mathrm{previously} \mathrm{used} \mathrm{successfully}$ to analyze IL-6-mediated regulation of hepatic detoxifying pathways in vitro (Le Vee et al., 2009; Klein et al., 2015). As shown in Table 1, this treatment was found to increase mRNA expression of CRP, a reference target of the signaling cascade IL-6/JAK1/STAT3 in human hepatocytes (Zhang et al., 1996). IL-6 concomitantly failed to exert cytotoxic effects, as shown by phase-contrast microscopic examination of the cultures (data not shown), which agrees with previous measurement of cellular viability in IL-6-treated human hepatocytes (Le Vee et al., 2009). In the presence of $5 \mu \mathrm{M}$ ruxolitinib, IL-6-induced CRP mRNA expression was
TABLE 1

Effects of ruxolitinib on IL-6 mediated induction of CRP mRNA levels in primary human hepatocytes and HepaRG cells ${ }^{a}$

\begin{tabular}{lcc}
\hline \multirow{2}{*}{ Treatment } & \multicolumn{2}{c}{ CRP mRNA Levels $^{b}$} \\
\cline { 2 - 3 } & Primary Human Hepatocytes & HepaRG Cells \\
\hline None (control) & $1.0 \pm 0.0$ & $1.0 \pm 0.0$ \\
Ruxolitinib & $0.2 \pm 0.0$ & $0.3 \pm 0.2$ \\
IL-6 & $6223 \pm 2667^{*}$ & $1258 \pm 125.7^{*}$ \\
Ruxolitinib/IL-6 & $0.2 \pm 0.0^{\S}$ & $0.3 \pm 0.1^{\S}$ \\
\hline
\end{tabular}

$* P<0.05$ when compared with control cells; ${ }^{\S} P<0.05$ when compared with IL-6-treated cells.

${ }^{a}$ Cells were either untreated (control), exposed to $5 \mu \mathrm{M}$ ruxolitinib or $10 \mathrm{ng} / \mathrm{ml} \mathrm{IL-6}$, or coexposed to $5 \mu \mathrm{M}$ ruxolitinib and $10 \mathrm{ng} / \mathrm{ml}$ IL- 6 for 24 hours. CRP mRNA expression was then determined by reverse transcription-quantitative polymerase chain reaction.

${ }^{b} \mathrm{CRP}$ mRNA levels are expressed comparatively to mRNA levels found in untreated control cells, arbitrarily set at $1 \mathrm{U}$; they are the means \pm S.E.M. of values from six independent human hepatocyte populations or five HepaRG cell cultures.

fully abolished in both primary human hepatocytes and HepaRG cells (Table 1), thus suggesting that ruxolitinib efficiently inhibited the IL-6/JAK/STAT pathway in these cultured hepatic cells. This hypothesis was fully confirmed by the fact that ruxolitinib fully antagonized IL-6-induced phosphorylation of STAT1 and its subsequent nuclear translocation in HepaRG cells (Supplemental Fig. 1).

Attenuation of IL-6-Mediated Repression of P450 Expression by Ruxolitinib in Primary Human Hepatocytes and HepaRG Cells. In agreement with previous studies (Abdel-Razzak et al., 1993; Aitken and Morgan, 2007) and in comparison with untreated cells, treatment of human hepatocytes by $10 \mathrm{ng} / \mathrm{ml}$ IL-6 for 24 hours was found to markedly repress mRNA expression of CYP1A2 (by $95.6 \% \pm 2.9 \%$ ), CYP2B6 (by $87.9 \% \pm 3.7 \%$ ), and CYP3A4 (by $97.1 \% \pm 2.1 \%$ ) in primary human hepatocytes (Fig. 1A). Ruxolitinib used at $5 \mu \mathrm{M}$ was able to fully reverse these IL-6-mediated suppressions of P450 mRNA expression (Fig. 1A). The JAK inhibitor was similarly efficient in abolishing mRNA repression of CYP1A2, CYP2B6, and CYP3A4 caused by longer exposures to IL-6 (48 and 72 hours) (Supplemental Fig. 2). Inhibitory effects of ruxolitinib toward IL-6-related suppression of P450 mRNAs in primary human hepatocytes were next shown to be dose-dependent, with $\mathrm{EC}_{50}$ values around $1.1 \mu \mathrm{M}$ for $\mathrm{CYP}_{3} \mathrm{~A} 4$ and around $1.2 \mu \mathrm{M}$ for CYP1A2 and CYP2B6 (Fig. 1B); similar ruxolitinib $\mathrm{EC}_{50}$ values were found for CYP1A2, CYP3A4, and CYP2B6 mRNA regulation in HepaRG cells (Supplemental Fig. 3). Hepatocyte population from each donor was fully responsive to IL-6, i.e., IL-6 repressed CYP3A4 mRNA levels by more than $97 \%$ for each of the analyzed hepatocyte population, and ruxolitinib $\mathrm{EC}_{50}$ values ranged from 1.01 to $1.15 \mu \mathrm{M}$ according to hepatocyte populations (data not shown), thus precluding any major interindividual difference for the response to the JAK inhibitor.

P450 mRNA and activity levels were next investigated in HepaRG cells exposed to $10 \mathrm{ng} / \mathrm{ml}$ IL- 6 for 48 hours. This treatment time was chosen owing to the known notable half-life of CYP3A4 protein and activity, estimated at 28.9 hours in IL-6-exposed human hepatocytes (Ramsden et al., 2015). IL-6 markedly reduced CYP1A2, CYP2B6, and CYP3A4 mRNA expression in HepaRG cells (Fig. 2A). These P450 mRNA repressions were associated with a concomitant significant reduction of CYP1A2, CYP2B6, and CYP3A4 activities (Fig. 2B); CYP1A2-related acetaminophen, CYP2B6-related hydroxybupropion and CYP3A4-related 1'-hydroxymidazolam formations measured by LC-MS/MS were thus reduced by $67.9 \pm 10.9 \%, 79.4 \pm 8.1 \%$, and $60.8 \pm 4.0 \%$, respectively, in response to exposure to IL-6. Ruxolitinib used at $5 \mu \mathrm{M}$ was found to counteract IL-6-mediated repression of CYP1A2, CYP26, and CYP3A4 at both mRNA (Fig. 2A) and activity (Fig. 2B) level. 
A

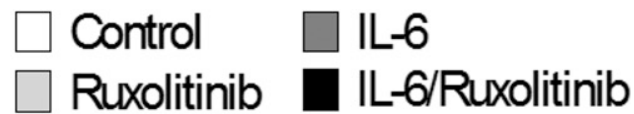

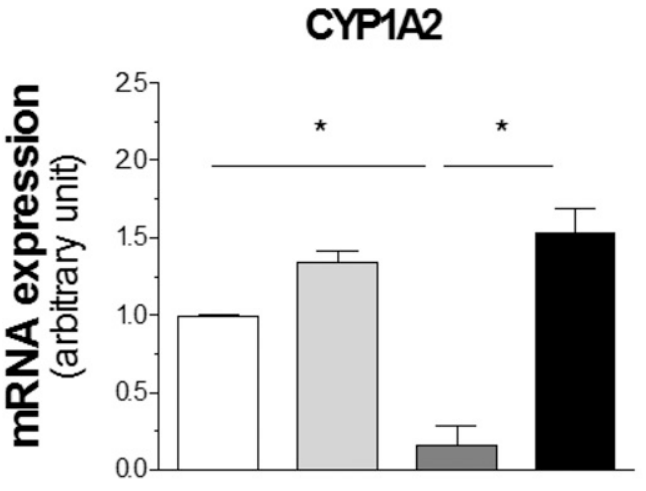

B

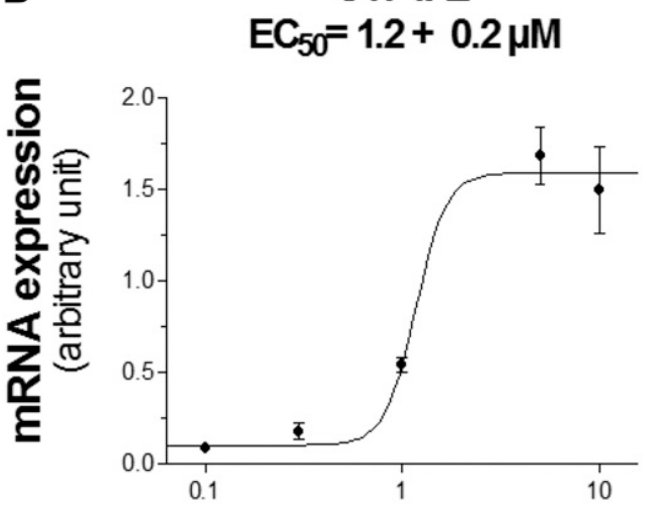

CYP2B6

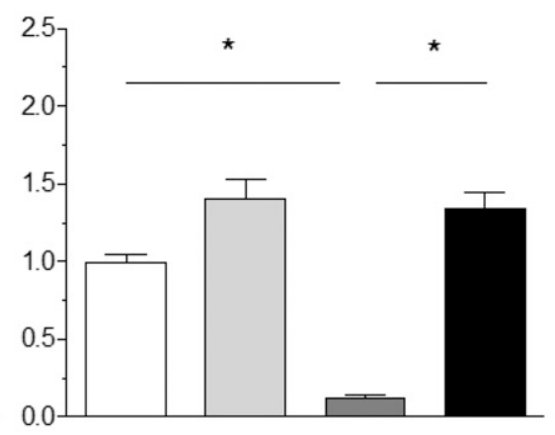

CYP2B6
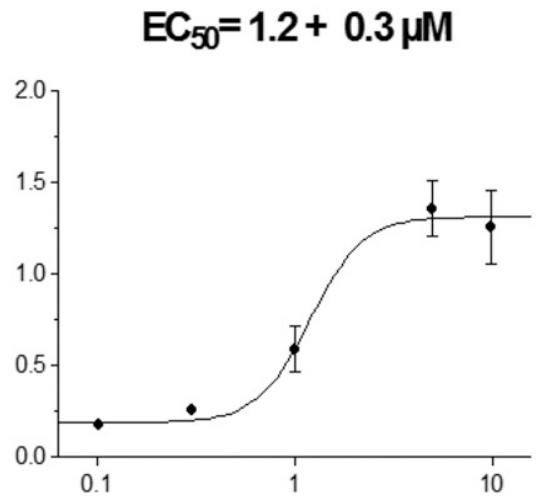

CYP3A4

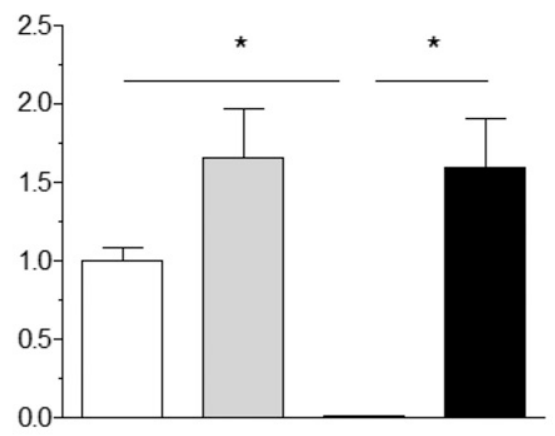

CYP3A4 $\mathrm{EC}_{50}=1.1 \pm 0.1 \mu \mathrm{M}$

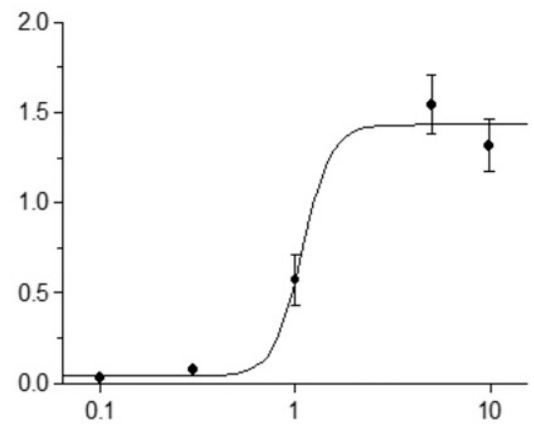

\section{Ruxolitinib ( $\mu \mathrm{M})$}

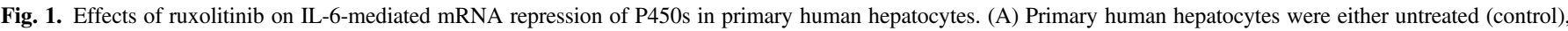

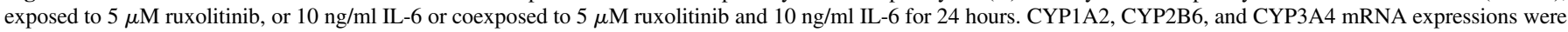

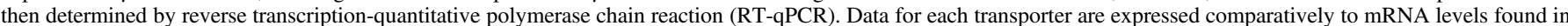

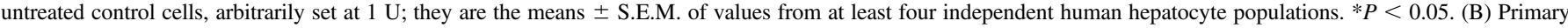

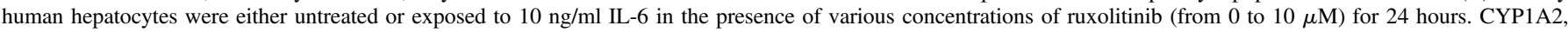

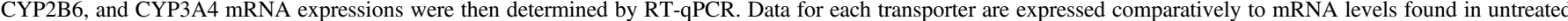

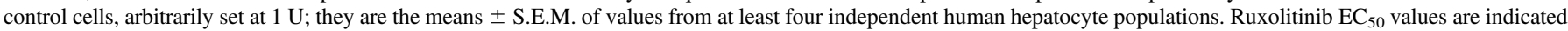
at the top of each graph.

Attenuation of IL-6-Mediated Repression of Drug Transporter Expression by Ruxolitinib in Primary Human Hepatocytes and HepaRG Cells. In agreement with previous studies (Le Vee et al., 2009; Yang et al., 2012) and in comparison with untreated cells, treatment of cultured human hepatocytes by $10 \mathrm{ng} / \mathrm{ml}$ IL- 6 for 24 hours was found to markedly repress mRNA expression of the drug transporters NTCP (by $98.0 \pm 0.5 \%$ ), OATP1B1 (SLCO1B1) (by $82.6 \pm 5.3 \%$ ), and OCT1 (by $75.2 \pm 3.9 \%$ ) (Fig. 3A). Ruxolitinib used at $5 \mu \mathrm{M}$ was able to reverse these IL-6-mediated suppressions of transporter mRNA expression (Fig. 3A). The JAK inhibitor was also fully efficient to abolish mRNA repression of NTCP, OATP1B1, and OCT1 caused by longer exposure to IL-6 (up to 72 hours) (Supplemental Fig. 4). Inhibitory effects of ruxolitinib toward IL-6-related suppression of transporter mRNAs in primary human hepatocytes were next shown to be dose-dependent, with $\mathrm{EC}_{50}$ values around $1.0 \mu \mathrm{M}$ (for OATP1B1 and OCT1) and $1.1 \mu \mathrm{M}$ (for NTCP) (Fig. 3B).

Treatment of HepaRG cells by $10 \mathrm{ng} / \mathrm{ml}$ IL-6 for 48 hours also markedly suppressed mRNA expression of NTCP, OATP1B1, and
OCT1 (Fig. 4A). It concomitantly reduced NTCP, OATP, and OCT1 transport activities (Fig. 4B), indicating functional repression of transporters by IL-6, in agreement with previous data (Le Vee et al., 2009). Sodium-dependent uptake of taurocholate, BSP-inhibitable uptake of E3S, and verapamil-inhibitable uptake of TEA were thus reduced by $62.4 \pm 18.0 \%, 46.3 \pm 5.8 \%$, and $53.0 \pm 18.5 \%$. Ruxolitinib used at $5 \mu \mathrm{M}$ was found to reverse IL-6-mediated repression of NTCP, OATP1B1, and OCT1 mRNA levels (Fig. 4A). It concomitantly inhibited IL-6-triggered decrease of NTCP, OATP, and OCT1 activity (Fig. 4B).

Lack of Ruxolitinib Effects Toward IL-1 $\beta$-Mediated Repression of P450 and Transporter mRNA Levels in HepaRG Cells. To evaluate the specificity of ruxolitinib toward cytokines like IL-6 acting via the JAK/STAT pathway, we next analyzed its potential effects toward IL- $1 \beta$-mediated alteration of detoxifying pathways in HepaRG cells. Indeed, IL- $1 \beta$ primarily acts by notably mobilizing myeloiddifferentiation primary response gene 88 (MYD88)/IL-1 receptoractivated protein kinases (IRAKs) $/ \mathrm{I} \kappa \mathrm{B}$ kinases $/ \mathrm{NF}-\kappa \mathrm{B}$, in a 

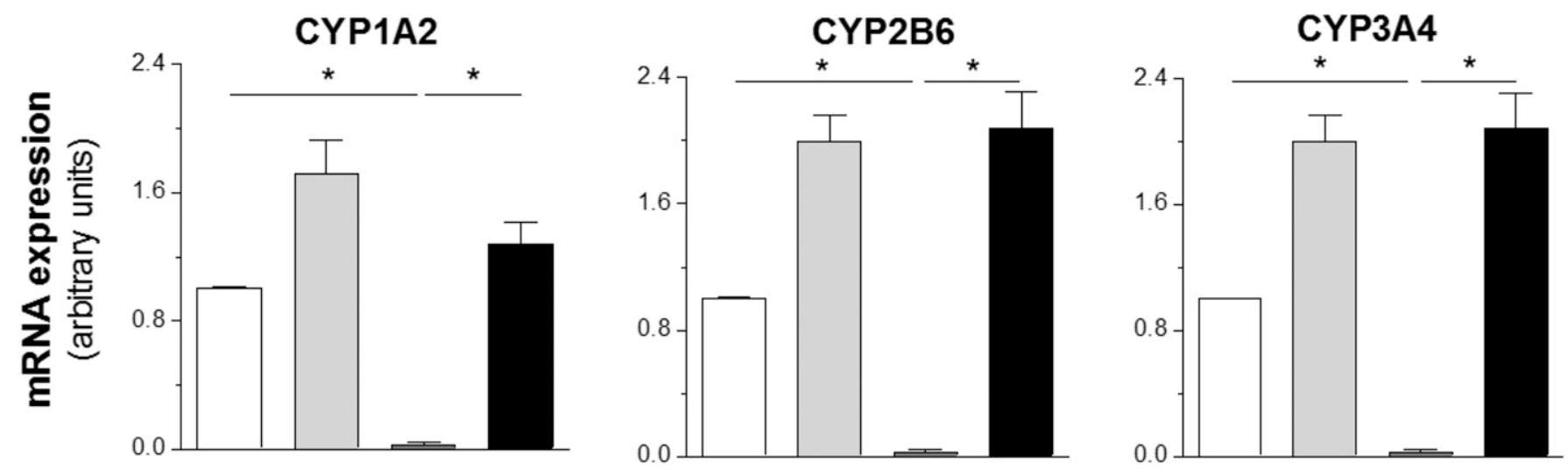

B
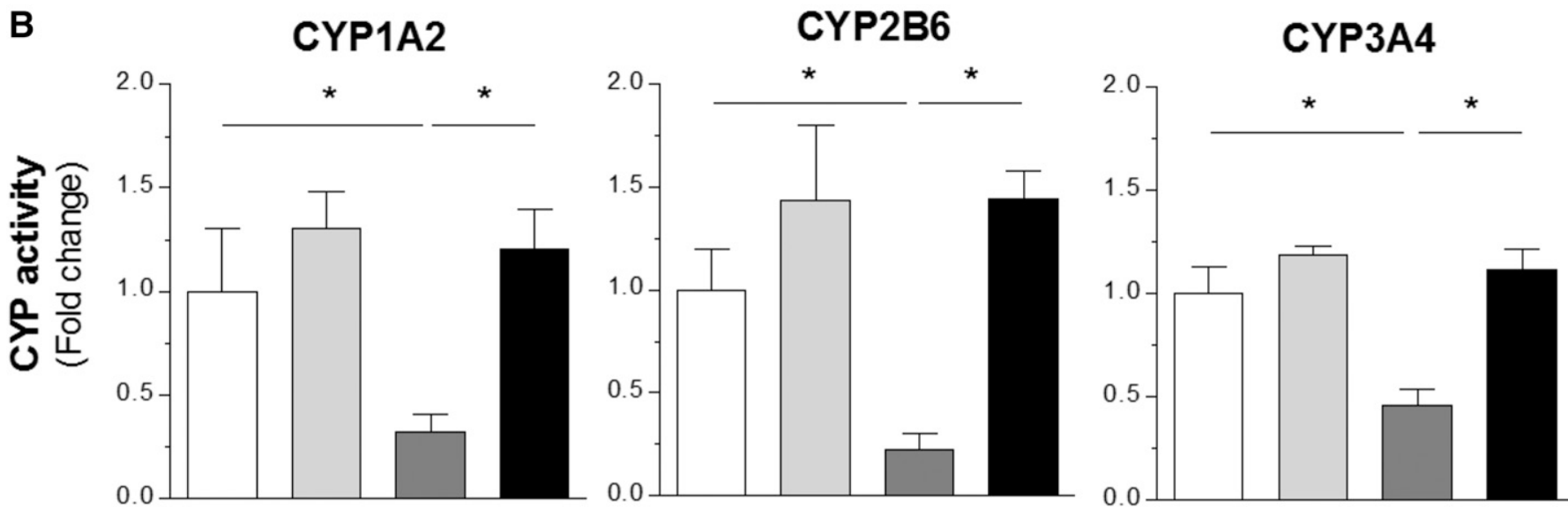

Fig. 2. Effects of ruxolitinib on IL-6-mediated repression of P450 mRNA (A) and activity (B) in human hepatoma HepaRG cells. HepaRG cells were either untreated (control), exposed to $5 \mu \mathrm{M}$ ruxolitinib or $10 \mathrm{ng} / \mathrm{ml} \mathrm{IL}-6$, or coexposed to $5 \mu \mathrm{M}$ ruxolitinib and $10 \mathrm{ng} / \mathrm{ml} \mathrm{IL}-6$ for 48 hours. (A) CYP1A2, CYP2B6, and CYP3A4 mRNA expressions were then determined by reverse transcription-quantitative polymerase chain reaction. Data for each P450 are expressed comparatively to mRNA levels found in untreated control cells, arbitrarily set at 1 U. (B) CYP1A2, CYP2B6, and CYP3A4 activities were determined by measuring the formation of acetaminophen, hydroxybupropion and 1'-hydroxy-midazolam, as described in Materials and Methods. Basal P450 activities in untreated control HepaRG cells were $3.4 \pm 1.0 \mathrm{pM}$ acetaminophen/mg protein per minute (CYP1A2 activity), $24.1 \pm 4.8 \mathrm{pM}$ hydroxy-bupropion/mg protein per minute (CYP2B6 activity), and $203.7 \pm 25.8 \mathrm{pM} 1{ }^{\prime}$-hydroxymidazolam/mg protein per minute (CYP3A4 activity). Data are expressed as fold-change when compared with P450 activities found in untreated control cells, i.e., as the ratio P450 activities in treated cells vs. that found in untreated cells. (A and B) Data are the means \pm S.E.M. of values from at least three independent assays. $* P<0.05$.

JAK-independent manner (Weber et al., 2010). IL-1 $\beta$ was used at $1 \mathrm{ng} / \mathrm{ml}$, a concentration previously demonstrated to repress many detoxifying proteins in human hepatocytes (Le Vee et al., 2008; Dickmann et al., 2012; Moreau et al., 2017). This IL-1 $\beta$ concentration did not trigger cytotoxicity, as shown by phase-contrast microscopic examination of the cultures (data not shown), which agrees with previous measurement of cellular viability in IL- $1 \beta$-treated HepaRG cells (Le Vee et al., 2008). IL-1 $\beta$ was found to highly induce mRNA expression of the inflammatory markers CRP and IL-8, as already reported (Le Vee et al., 2008), and to significantly reduce those of various P450s and transporters (Fig. 5). CYP1A2 and CYP3A4 mRNA levels were thus highly reduced by $99.1 \pm 0.3 \%$ and $98.5 \pm 0.4 \%$, respectively, and those of NTCP, OATP1B1, and OCT1 were markedly decreased by $91.8 \pm 7.6 \%, 92.8 \pm 2.5 \%$, and $67.7 \pm 13.9 \%$, respectively. Such potent repressions of drug-detoxifying protein
mRNA levels in response to Il- $1 \beta$ were not significantly impaired by $5 \mu \mathrm{M}$ ruxolitinib (Fig. 5). Similarly, IL- $1 \beta$-mediated upregulation of IL-8 was not counteracted by ruxolitinib, which, by contrast, inhibited that of CRP (Fig. 5), suggesting an implication of the JAK/STAT pathway in CRP upregulation by IL- $1 \beta$.

Attenuation of IL-6-Mediated Repression of P450 and Drug Transporter mRNA Levels by the JAK1/3 Inhibitor Tofacitinib in HepaRG Cells. To determine whether JAK inhibitors structurally distinct from ruxolitinib can also reverse IL-6-mediated suppression of detoxifying protein, we analyzed the effects of tofacitinib (also known as CP-690,550), a marketed JAK1/3 inhibitor currently used for the treatment of rheumatoid arthritis (Vyas et al., 2013). Here, tofacitinib was used at a $3 \mu \mathrm{M}$ concentration, which may be reached in plasma of patients treated by oral administration of this JAK inhibitor (Dowty et al., 2014; Krishnaswami et al., 2015). At this concentration, tofacitinib 
A Control $\square$ IL-6
Ruxolitinib $\square$ IL-6/Ruxolitinib
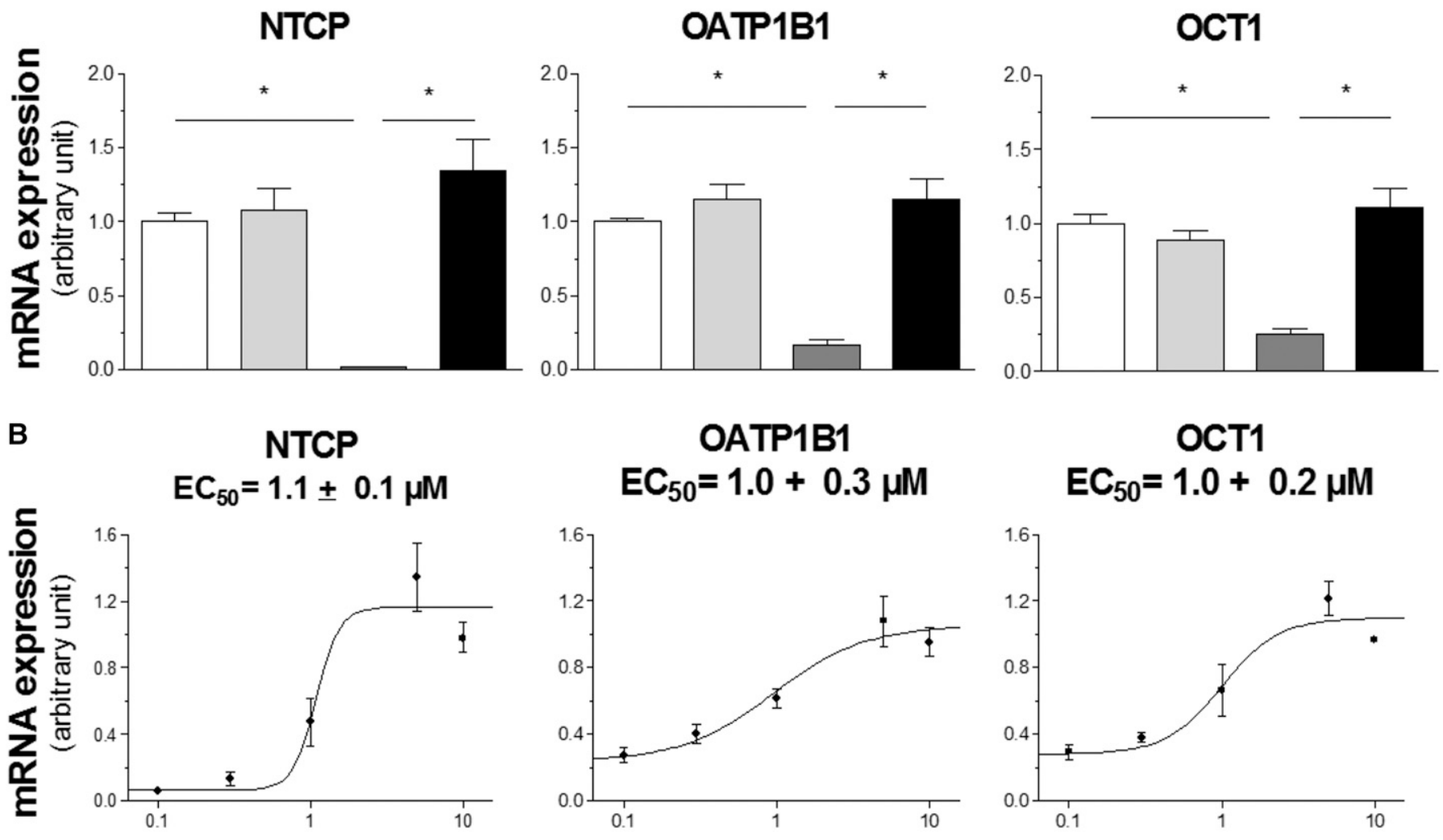

Ruxolitinib ( $\mu \mathrm{M})$

Fig. 3. Effects of ruxolitinib on IL-6-mediated mRNA repression of drug transporters in primary human hepatocytes. (A) Primary human hepatocytes were either untreated

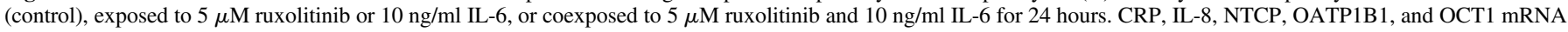
expressions were then determined by reverse transcription-quantitative polymerase chain reaction (RT-qPCR). Data for each transporter are expressed comparatively to mRNA levels found in untreated control cells, arbitrarily set at $1 \mathrm{U}$; they are the means \pm S.E.M. of values from at least four independent human hepatocyte populations. $* P<0.05$. (B) Primary human hepatocytes were either untreated or exposed to $10 \mathrm{ng} / \mathrm{ml} \mathrm{IL}-6$ in the presence of various concentrations of ruxolitinib (from 0 to $10 \mu \mathrm{M}$ ) for 24 hours. NTCP, OATP1B1, and OCT1 mRNA expressions were then determined by RT-qPCR. Data for each transporter are expressed comparatively to mRNA levels found in untreated control cells, arbitrarily set at $1 \mathrm{U}$; they are the means \pm S.E.M. of values from at least three independent human hepatocyte populations. Ruxolitinib EC 50 values are indicated at the top of each graph.

was found to fully reverse IL-6-mediated mRNA induction of the reference target CRP in HepaRG cells (Fig. 6), thus demonstrating that tofacitinib, as ruxolitinib, was efficient to antagonize the JAK/STAT pathway mobilized by IL-6 in such cells. Tofacitinib was next shown to counteract repression of CYP1A2, CYP2B6, CYP3A4, NTCP, OATP1B1, and OCT1 mRNA levels caused by IL-6 in HepaRG cells (Fig. 6).

\section{Discussion}

The data reported in the present study indicate that the marketed JAK1/2 inhibitor ruxolitinib can markedly reverse IL-6-mediated repression of hepatic drug-detoxifying proteins in vitro. Ruxolitinib notably restores mRNA expression of both drug-metabolizing enzymes and sinusoidal drug transporters in primary human hepatocytes and HepaRG cells exposed to IL-6. These ruxolitinib effects are rather specific, as the JAK $1 / 2$ inhibitor failed to hinder IL- $1 \beta$-mediated mRNA suppression of drug-detoxifying proteins. Also, tofacitinib, another JAK inhibitor not structurally related to ruxolitinib, counteracted P450 and drug transporter suppression owing to IL-6 as well. Furthermore, ruxolitinib concentrations (in the $1 \mu \mathrm{M}$ range) required to reverse IL-6-mediated repression of detoxifying pathways in primary human hepatocytes were close to those (in the $0.25-1 \mu \mathrm{M}$ range) previously demonstrated to be needed to efficiently counteract the JAK/STAT pathway in cultured cells (Schönberg et al., 2015). These ruxolitinib effects toward drug-detoxifying protein expression consequently most probably implicate its basic inhibitory activity against the JAK/STAT pathway. A role for off-target effects of ruxolitinib, which notably concerns various kinases such as tropomyosin receptor kinase B, activated CDC42 kinase 1, anaplastic lymphoma kinase, RET kinase, and Rho-associated protein kinases (Zhou et al., 2014; Rudolph et al., 2016), has thus to be discarded. Importantly, the IL-6 concentration used in the present study $(10 \mathrm{ng} / \mathrm{ml})$ has to be considered as supraphysiologic. Indeed, in healthy individuals, serum IL-6 concentrations usually range from 1.3 to $10.3 \mathrm{pg} / \mathrm{ml}$ and are increased to $2.6-123 \mathrm{pg} / \mathrm{ml}$ in some patient populations suffering from inflammation-based diseases 
A
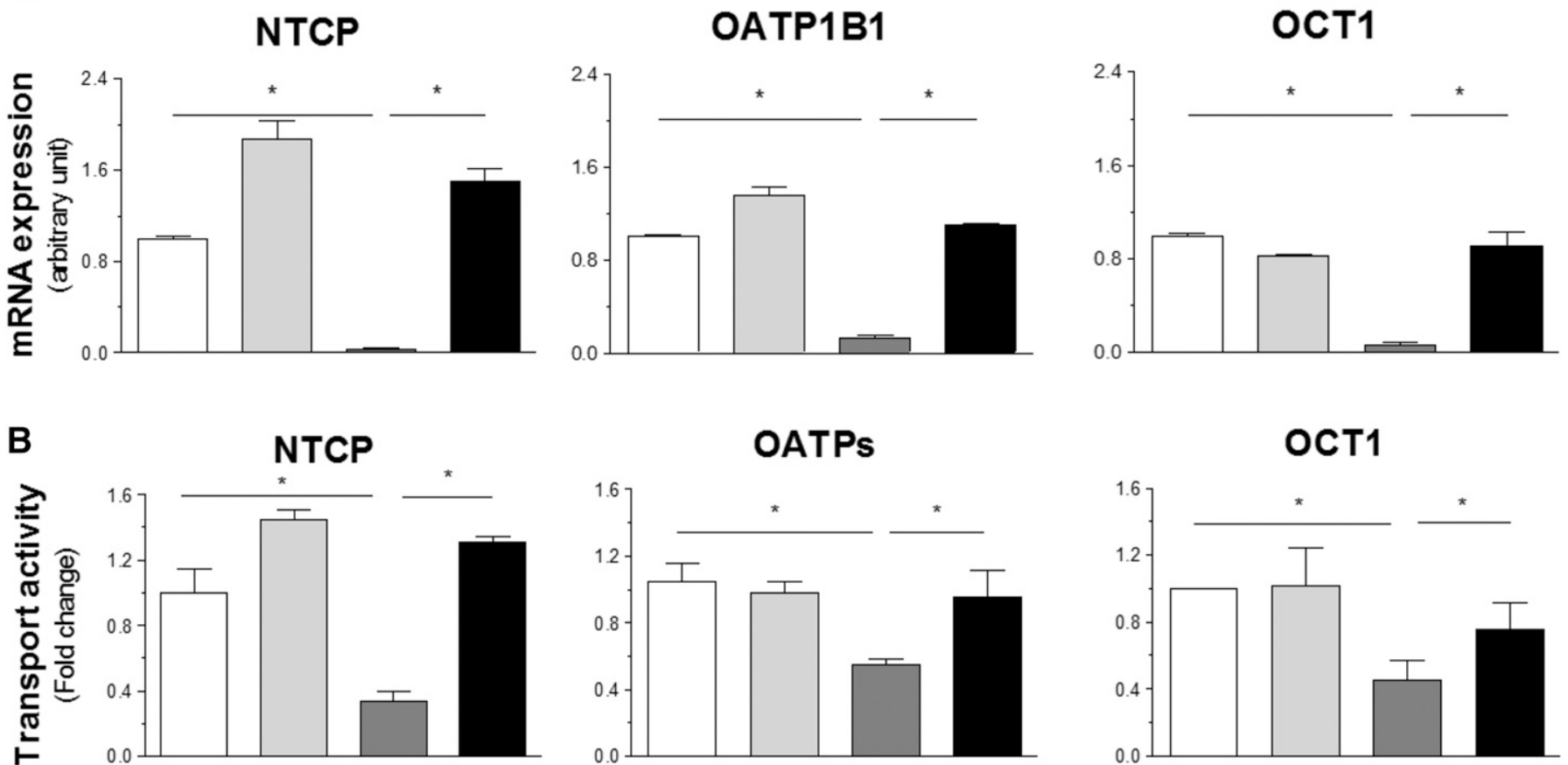

Fig. 4. Effects of ruxolitinib on IL-6-mediated repression of drug transporter mRNA (A) and activity (B) in human hepatoma HepaRG cells. HepaRG cells were either untreated (control), exposed to $5 \mu \mathrm{M}$ ruxolitinib or $10 \mathrm{ng} / \mathrm{ml} \mathrm{IL}-6$, or coexposed to $5 \mu \mathrm{M}$ ruxolitinib and $10 \mathrm{ng} / \mathrm{ml}$ IL-6 for 48 hours. (A) NTCP, OATP1B1, and OCT1 mRNA expressions were then determined by reverse transcription-quantitative polymerase chain reaction. Data for each transporter are expressed comparatively to mRNA levels found in untreated control cells, arbitrarily set at $1 \mathrm{U}$. (B) NTCP, OATP1B1, and OCT1 activities were determined by measuring sodium-dependent uptake of taurocholate, BSP-inhibitable uptake of E3S, and verapamil-inhibitable uptake of TEA, as described in Materials and Methods. Data are expressed as fold-change when compared with transporter activities found in untreated control cells, i.e., as the ratio of transporter activity in treated cells vs. that found in untreated cells. Absolute levels of transporter-mediated uptake of substrates in untreated control HepaRG cells were $1.59 \pm 0.34 \mathrm{pmol} / \mathrm{mg}$ protein (taurocholate), $0.35 \pm 0.05 \mathrm{pmol} / \mathrm{mg}$ protein (E3S), and $148.5 \pm 76.9 \mathrm{pmol} / \mathrm{mg}$ protein (TEA). (A and B) Data are the means \pm S.E.M. of values from at least three independent assays. $* P<0.05$.

(Dickmann et al., 2011). Ruxolitinib has therefore to be considered as fully efficient to counteract effects of IL-6, even if the cytokine is used at very high concentrations. By contrast, TPs acting as IL-6- or IL- $1 \beta$ neutralizing mAbs attenuate, but not fully abolish, IL-6- or IL- $1 \beta$ mediated repression of CYP3A4 by shifting cytokine half-maximal inhibitory concentration $\left(\mathrm{IC}_{50}\right)$ toward higher values (Dickmann et al., 2011; Moreau et al., 2017).

It is noteworthy that ruxolitinib $\mathrm{EC}_{50}$ values (in the $1 \mu \mathrm{M}$ range) needed to abrogate IL-6 effects toward drug-detoxifying proteins in cultured human hepatocytes are much higher than those (in the $5 \mathrm{nM}$ range) required to inhibit JAK1 and JAK2 activities in acellular system assays (Fridman et al., 2010). This may reflect the fact that active free concentrations of ruxolitinib, known to be highly bound to circulating proteins in the human plasma (unbound plasma concentration $=3.3 \%$ ) (Shi et al., 2015), are probably low in the FBS-supplemented culture medium used for the in vitro treatment of hepatocytes in the present study. Moreover, intracellular hepatic concentrations of unbound ruxolitinib, which remain to be characterized, probably need to be taken into account, because ruxolitinib primarily acts intracellularly, i.e., it blocks JAKs located at the cytoplasmic face of the IL-6 receptor. Finally, metabolic degradation of ruxolitinib by drug-metabolizing enzymes, especially CYP3A4 (Shi et al., 2012), may additionally contribute to the relatively high $\mathrm{EC}_{50}$ values of ruxolitinib observed in metabolically competent human hepatocytes.

The marked upregulation of functional drug-detoxifying protein expression by ruxolitinib in IL-6-treated human hepatocyte cultures suggests that the JAK1/2 inhibitor may cause idDDIs in patients suffering from inflammatory or infectious diseases by enhancing detoxification capacities. This hypothesis is fully supported by the fact that other drugs targeting the IL-6 pathway, such as the mAbs tocilizumab, sarilumab, and sirukumab, have been shown to reduce exposure of coadministrated drugs like simvastatin, midazolam, or omeprazole (Schmitt et al., 2011; Zhuang et al., 2015; Lee et al., 2017). Moreover, ruxolitinib concentrations required to counteract IL-6mediated suppression of P450s and drug transporters in vitro are in the $1.0-1.2 \mu \mathrm{M}$ range, which is close to the range of ruxolitinib maximum plasma concentrations $\left(\mathrm{C}_{\max } ; 0.59-1.29 \mu \mathrm{M}\right)$ reached in patients treated with the JAK inhibitor (Ogama et al., 2013). In addition, ruxolitinib in vitro effects toward IL-6-related P450 and transporter repression seem to be not transient, i.e., they lasted at least 72 hours in cultured human hepatocytes. The clinical use of ruxolitinib may therefore be theoretically efficient to counteract the repressing effect of IL-6 toward drug-detoxifying pathways in vivo. However, such an effect, and the potential consequences in terms of idDDIs, have not 
$\square$ Control $\square$ IL-1 $\beta$

Ruxolitinib IL-1 $\square /$ Ruxolitinib
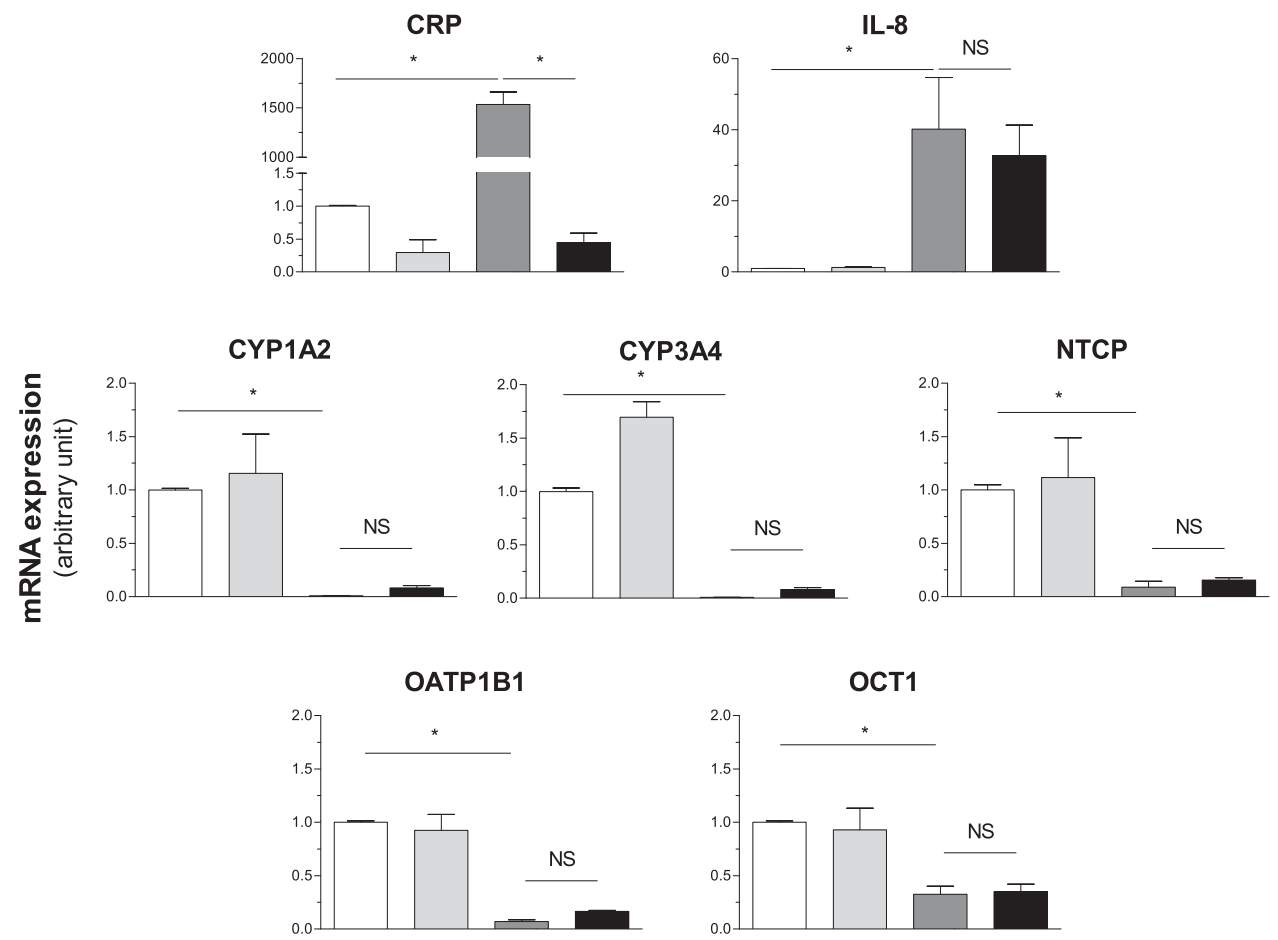

Fig. 5. Effects of ruxolitinib on IL-1 $\beta$ mediated repression of $\mathrm{P} 450$ and transporter mRNA levels in human hepatoma HepaRG cells. HepaRG cells were either untreated (control), exposed to $5 \mu \mathrm{M}$ ruxolitinib or $1 \mathrm{ng} / \mathrm{ml}$ $\mathrm{IL}-1 \beta$, or coexposed to $5 \mu \mathrm{M}$ ruxolitinib and $1 \mathrm{ng} / \mathrm{ml} \mathrm{IL-} 1 \beta$ for 24 hours. (A) CRP, IL-8, CYP1A2, CYP3A4, NTCP, OATP1B1, and OCT1 mRNA expressions were then determined by reverse transcription-quantitative polymerase chain reaction. Data for each drug-detoxifying protein are expressed comparatively to mRNA levels found in untreated control cells, arbitrarily set at $1 \mathrm{U}$. Data are the means \pm S.E.M. of values from at least five independent assays. ${ }^{*} P<0.05$; NS, not statistically significant $(P>0.05)$. presently been reported in the literature, according to the best of our knowledge. Similarly, tofacitinib, although efficiently counteracting P450 and transporter repression caused by IL-6 in hepatic HepaRG cells, has not been shown to cause clinical idDDIs through enhancing drug metabolism and/or transport. Notably, tofacitinib did not alter the pharmacokinetics of the reference CYP3A4 substrate midazolam in healthy volunteers (Gupta et al., 2012). It similarly failed to impair pharmacokinetics of oral contraceptive steroids in healthy female volunteers (Menon et al., 2016). Nevertheless, it is noteworthy that these pharmacokinetics studies were performed in healthy subjects, who probably would not have exhibited inflammation-related altered physiologic functions, such as IL-6-mediated repression of hepatic detoxifying pathways. By contrast, patients suffering from myeloproliferative neoplasms or rheumatoid arthritis, which correspond to present clinical indications for ruxolitinib and tofacitinib, respectively, commonly exhibit increased plasma levels of IL-6 (Čokić et al., 2015; do Prado et al., 2016; Sollazzo et al., 2016). Pharmacokinetic studies centered on such patients are probably required therefore to verify the hypothesis that marketed JAK inhibitors, including not only ruxolitinib and tofacitinib, but also baricitinib, very recently approved in European Union for rheumatoid arthritis treatment (Richez et al., 2017), may cause idDDIs through antagonizing the IL-6/JAK/STAT pathway.

It is noteworthy that both ruxolitinib and tofacitinib are primarily metabolized by CYP3A4, which thus appears as a key factor for their detoxification (Shi et al., 2012; Dowty et al., 2014). Inhibition of CYP3A4 activity by ketoconazole notably has been shown to increase total ruxolitinib plasma exposure, whereas induction of CYP3A4 expression by rifampicin decreased it in healthy volunteers (Shi et al., 2012). Through restoring functional expression of hepatic CYP3A4 in patients displaying elevated levels of IL-6, ruxolitinib and tofacitinib may therefore induce their own metabolism. Finally, it is noteworthy that ruxolitinib and tofacitinib reduce plasma levels of IL-6 and other inflammatory cytokines in patients to whom they are administrated (Migita et al., 2014; Tabarroki et al., 2014). Such a downregulation of inflammatory cytokines may also contribute to putative in vivo inhibition of inflammation-related repression of hepatic detoxifying pathway by the JAK inhibitors.

Both primary human hepatocytes and HepaRG cells were found to be well responsive to IL- 6 and ruxolitinib, thus demonstrating that these cellular models are probably relevant for studying the interactions of small drugs with inflammatory cytokines in vitro. Cultured human hepatocytes have similarly been used to investigate the effects of TPS toward cytokine-driven regulation of P450s and transporters (Dickmann et al., 2011; Moreau et al., 2017). Their relevance for the prediction of TP-idDDIs may however be compromised because of the high interlaboratory variability in P450 suppression by cytokines (Evers et al., 2013). In this context, it is noteworthy that the rather elevated concentration of IL-6 used in the study $(10 \mathrm{ng} / \mathrm{ml})$ allowed for high repression of CYP3A4 mRNA in the human hepatocyte population analyzed from each donor; other drug-detoxifying proteins, including CYP1A2, CYP2B6, NTCP, OATP1B1, and OCT1, were also markedly repressed, regardless of the hepatocyte population (data not shown). In addition, ruxolitinib was likewise efficient in counteracting IL-6-related repression of CYP3A4 mRNAs in the human hepatocyte population of each donor. Taken together, these data suggest that interindividual variations in ruxolitinib response may be rather negligible in our experimental conditions. Besides, it should be kept in mind that inflammatory diseases display complex biology, with frequent implication of multiple cytokines, which may interact with one another. The hepatocyte monoculture has consequently been considered as an oversimplified system, which cannot reproduce the complex biology of in vivo inflammatory disease states (Girish et al., 2011; Evers et al., 2013). The analysis of JAK inhibitor effects toward cytokine-regulated detoxifying proteins in a more relevant in vitro model, such as the 

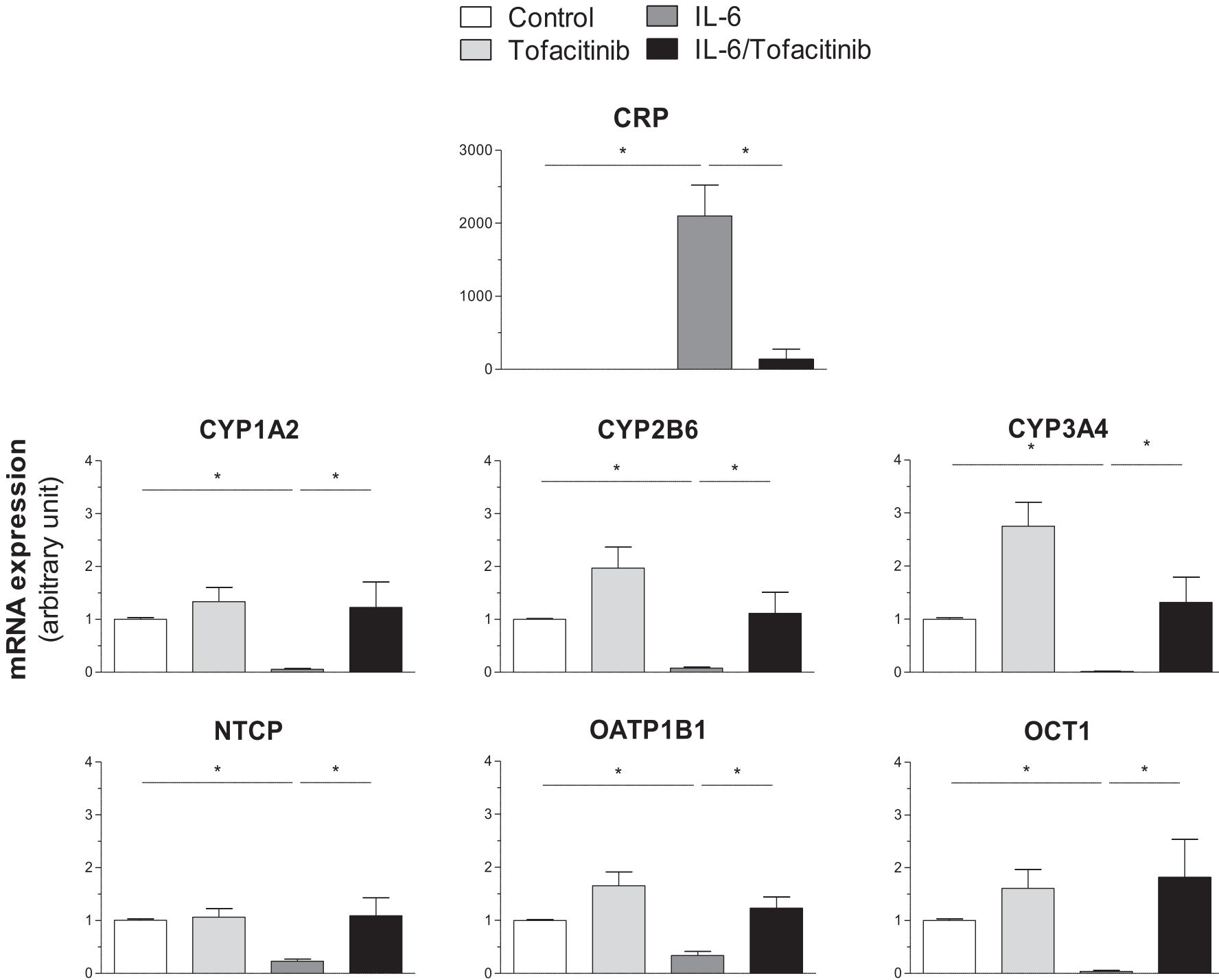

Fig. 6. Effects of tofacitinib on IL-6-mediated repression of P450 and drug transporter mRNA levels in human hepatoma HepaRG cells. HepaRG cells were either untreated (control), exposed to $3 \mu \mathrm{M}$ tofacitinib or $10 \mathrm{ng} / \mathrm{ml} \mathrm{IL}-6$, or coexposed to $3 \mu \mathrm{M}$ tofacitinib and $10 \mathrm{ng} / \mathrm{ml} \mathrm{IL}-6$ for 24 hours. CRP, P450, and drug transporter mRNA expressions were then determined by reverse transcription-quantitative polymerase chain reaction. Data are expressed comparatively to mRNA levels found in untreated control cells, arbitrarily set at $1 \mathrm{U}$; they are the means \pm S.E.M. of values from four independent assays. $* P<0.05$.

hepatocyte-Kupffer cell coculture system (Nguyen et al., 2015), would be welcome.

In summary, the JAK inhibitor ruxolitinib was shown to potently counteract the repressing effects of IL-6 toward hepatic P450s and drug transporters. This may be the source of potential idDDIs, through a new mechanism, i.e., a small drug (ruxolitinib) acting as a perpetrator by restoring full hepatic detoxification capacities for patients suffering from inflammation-based diseases. This point probably deserves attention, owing to the growing interest in clinical use of ruxolitinib, tofacitinib, baricitinib, and other JAK inhibitors currently in development for the treatment of various inflammatory and autoimmune diseases (Banerjee et al., 2017).

\section{Acknowledgments}

The authors thank Dr. Valérie Lecureur for critical reading of the manuscript, Dr. Sylvie Hermouet for her helpful encouragement to their work, Dr. Abdullah Mayati for his help with immunocytochemistry, Dr. Bruno Turlin and the Centre de Ressources Biologiques (CRB) Santé of Rennes BB-0033-00056 for managing patient samples, and Technologie Servier (Orléans, France) for the gift of the LC-MS/MS system.

\section{Authorship Contributions}

Participated in research design: Febvre-James, Fardel.

Conducted experiments: Febvre-James, Bruyère.

Contributed new reagents or analytic tools: Bruyère, Le Vée.

Performed data analysis: Febvre-James, Fardel.

Wrote or contributed to the writing of the manuscript: Febvre-James, Bruyère, Fardel.

\section{References}

Abdel-Razzak Z, Loyer P, Fautrel A, Gautier JC, Corcos L, Turlin B, Beaune P, and Guillouzo A (1993) Cytokines down-regulate expression of major cytochrome P-450 enzymes in adult human hepatocytes in primary culture. Mol Pharmacol 44:707-715.

Aitken AE and Morgan ET (2007) Gene-specific effects of inflammatory cytokines on cytochrome P450 2C, 2B6 and 3A4 mRNA levels in human hepatocytes. Drug Metab Dispos 35:1687-1693. Baker KF and Isaacs JD (2017) Novel therapies for immune-mediated inflammatory diseases: what can we learn from their use in rheumatoid arthritis, spondyloarthritis, systemic lupus erythematosus, psoriasis, Crohn's disease and ulcerative colitis? Ann Rheum Dis [published ahead of print].

Banerjee S, Biehl A, Gadina M, Hasni S, and Schwartz DM (2017) JAK-STAT signaling as a target for inflammatory and autoimmune diseases: current and future prospects. Drugs 77:521-546.

Bose P and Verstovsek S (2017) JAK2 inhibitors for myeloproliferative neoplasms: what is next? Blood 130:115-125.

Bradford MM (1976) A rapid and sensitive method for the quantitation of microgram quantities of protein utilizing the principle of protein-dye binding. Anal Biochem 72:248-254.

Cascorbi I (2012) Drug interactions-principles, examples and clinical consequences. Dtsch Arztebl Int 109:546-555, quiz 556 
Čokić VP, Mitrović-Ajtić O, Beleslin-Čokić BB, Marković D, Buač M, Diklić M, KraguljacKurtović N, Damjanović S, Milenković P, Gotić M, et al. (2015) Proinflammatory cytokine IL-6 and JAK-STAT signaling pathway in myeloproliferative neoplasms. Mediators Inflamm 2015: 453020.

Danton AC, Montastruc F, Sommet A, Durrieu G, Bagheri H, Bondon-Guitton E, Lapeyre-Mestre M, and Montastruc JL (2013) Importance of cytochrome P450 (CYP450) in adverse drug reactions due to drug-drug interactions: a PharmacoVigilance study in France. Eur J Clin Pharmacol 69:885-888.

Dickmann LJ, Patel SK, Rock DA, Wienkers LC, and Slatter JG (2011) Effects of interleukin-6 (IL-6) and an anti-IL-6 monoclonal antibody on drug-metabolizing enzymes in human hepatocyte culture. Drug Metab Dispos 39:1415-1422

Dickmann LJ, Patel SK, Wienkers LC, and Slatter JG (2012) Effects of interleukin $1 \beta$ (IL-1 $\beta$ ) and IL-1 $\beta$ /interleukin 6 (IL-6) combinations on drug metabolizing enzymes in human hepatocyte culture. Curr Drug Metab 13:930-937.

do Prado AD, Bisi MC, Piovesan DM, Bredemeier M, Batista TS, Petersen L, Bauer ME, da Silveira IG, Mendonç JA, and Staub HL (2016) Ultrasound power Doppler synovitis is associated with plasma IL-6 in established rheumatoid arthritis. Cytokine 83:27-32.

Dowty ME, Lin J, Ryder TF, Wang W, Walker GS, Vaz A, Chan GL, Krishnaswami S, and Prakash C (2014) The pharmacokinetics, metabolism, and clearance mechanisms of tofacitinib, a janus kinase inhibitor, in humans. Drug Metab Dispos 42:759-773.

Evers R, Dallas S, Dickmann LJ, Fahmi OA, Kenny JR, Kraynov E, Nguyen T, Patel AH, Slatter JG, and Zhang L (2013) Critical review of preclinical approaches to investigate cytochrome $\mathrm{p} 450$-mediated therapeutic protein drug-drug interactions and recommendations for best practices: a white paper. Drug Metab Dispos 41:1598-1609.

Fardel O and Le Vée M (2009) Regulation of human hepatic drug transporter expression by proinflammatory cytokines. Expert Opin Drug Metab Toxicol 5:1469-1481.

Fardel O, Morel F, and Guillouzo A (1993) P-glycoprotein expression in human, mouse, hamster and rat hepatocytes in primary culture. Carcinogenesis 14:781-783.

Fridman JS, Scherle PA, Collins R, Burn TC, Li Y, Li J, Covington MB, Thomas B, Collier P, Favata MF, et al. (2010) Selective inhibition of JAK1 and JAK2 is efficacious in rodent models of arthritis: preclinical characterization of INCB028050. J Immunol 184:5298-5307.

Girish S, Martin SW, Peterson MC, Zhang LK, Zhao H, Balthasar J, Evers R, Zhou H, Zhu M, Klunk L, et al. (2011) AAPS workshop report: strategies to address therapeutic protein-drug interactions during clinical development. AAPS $J$ 13:405-416.

Gripon P, Rumin S, Urban S, Le Seyec J, Glaise D, Cannie I, Guyomard C, Lucas J, Trepo C, and Guguen-Guillouzo C (2002) Infection of a human hepatoma cell line by hepatitis B virus. Proc Natl Acad Sci USA 99:15655-15660.

Gupta P, Alvey C, Wang R, Dowty ME, Fahmi OA, Walsky RL, Riese RJ, and Krishnaswami S (2012) Lack of effect of tofacitinib (CP-690,550) on the pharmacokinetics of the CYP3A4 substrate midazolam in healthy volunteers: confirmation of in vitro data. $\mathrm{Br} J$ Clin Pharmacol 74:109-115.

Harvey RD and Morgan ET (2014) Cancer, inflammation, and therapy: effects on cytochrome p450-mediated drug metabolism and implications for novel immunotherapeutic agents. Clin Pharmacol Ther 96:449-457.

Hunter CA and Jones SA (2015) IL-6 as a keystone cytokine in health and disease. Nat Immuno 16:448-457.

Jiang X, Zhuang Y, Xu Z, Wang W, and Zhou H (2016) Development of a physiologically based pharmacokinetic model to predict disease-mediated therapeutic protein-drug interactions: modulation of multiple cytochrome P450 enzymes by interleukin-6. AAPS J 18:767-776.

Jigorel E, Le Vee M, Boursier-Neyret C, Bertrand M, and Fardel O (2005) Functional expression of sinusoidal drug transporters in primary human and rat hepatocytes. Drug Metab Dispos 33: $1418-1422$.

Jigorel E, Le Vee M, Boursier-Neyret C, Parmentier Y, and Fardel O (2006) Differential regulation of sinusoidal and canalicular hepatic drug transporter expression by xenobiotics activating drugsensing receptors in primary human hepatocytes. Drug Metab Dispos 34:1756-1763.

Klein M, Thomas M, Hofmann U, Seehofer D, Damm G, and Zanger UM (2015) A systematic comparison of the impact of inflammatory signaling on absorption, distribution, metabolism, and excretion gene expression and activity in primary human hepatocytes and HepaRG cells. Drug Metab Dispos 43:273-283.

Krishnaswami S, Boy M, Chow V, and Chan G (2015) Safety, tolerability, and pharmacokinetics of single oral doses of tofacitinib, a Janus kinase inhibitor, in healthy volunteers. Clin Pharmacol Drug Dev 4:83-88.

Le Vee M, Gripon P, Stieger B, and Fardel O (2008) Down-regulation of organic anion transporter expression in human hepatocytes exposed to the proinflammatory cytokine interleukin 1beta. Drug Metab Dispos 36:217-222.

Le Vee M, Lecureur V, Stieger B, and Fardel O (2009) Regulation of drug transporter expression in human hepatocytes exposed to the proinflammatory cytokines tumor necrosis factor-alpha or interleukin-6. Drug Metab Dispos 37:685-693.

Le Vee M, Noel G, Jouan E, Stieger B, and Fardel O (2013) Polarized expression of drug transporters in differentiated human hepatoma HepaRG cells. Toxicol In Vitro 27:1979-1986.

Lee EB, Daskalakis N, Xu C, Paccaly A, Miller B, Fleischmann R, Bodrug I, and Kivitz A (2017) Disease-drug interaction of sarilumab and simvastatin in patients with rheumatoid arthritis. Clin Pharmacokinet 56:607-615.

Menon S, Riese R, Wang R, Alvey CW, Shi H, Petit W, and Krishnaswami S (2016) Evaluation of the effect of tofacitinib on the pharmacokinetics of oral contraceptive steroids in healthy female volunteers. Clin Pharmacol Drug Dev 5:336-342.

Migita K, Izumi Y, Jiuchi Y, Kozuru H, Kawahara C, Izumi M, Sakai T, Nakamura M, Motokawa S, Nakamura T, et al. (2014) Effects of Janus kinase inhibitor tofacitinib on circulating serum amyloid A and interleukin-6 during treatment for rheumatoid arthritis. Clin Exp Immunol 175 : 208-214.

Moreau A, Le Vée M, Jouan E, Denizot C, Parmentier Y, and Fardel O (2017) Effect of gevokizumab on interleukin-1 $\beta$-mediated cytochrome P450 3A4 and drug transporter repression in cultured human hepatocytes. Eur J Drug Metab Pharmacokinet 42:871-878.

Morgan ET (2009) Impact of infectious and inflammatory disease on cytochrome P450-mediated drug metabolism and pharmacokinetics. Clin Pharmacol Ther 85:434-438.

Morgan ET, Goralski KB, Piquette-Miller M, Renton KW, Robertson GR, Chaluvadi MR, Charles KA, Clarke SJ, Kacevska M, Liddle C, et al. (2008) Regulation of drug-metabolizing enzymes and transporters in infection, inflammation, and cancer. Drug Metab Dispos 36:205-216.

Nguyen TV, Ukairo O, Khetani SR, McVay M, Kanchagar C, Seghezzi W, Ayanoglu G, Irrechukwu O, and Evers R (2015) Establishment of a hepatocyte-kupffer cell coculture model for assessment of proinflammatory cytokine effects on metabolizing enzymes and drug transporters. Drug Metab Dispos 43:774-785.

Ogama Y, Mineyama T, Yamamoto A, Woo M, Shimada N, Amagasaki T, and Natsume K (2013) A randomized dose-escalation study to assess the safety, tolerability, and pharmacokinetics of ruxolitinib (INC424) in healthy Japanese volunteers. Int J Hematol 97:351-359.

Prueksaritanont T, Chu X, Gibson C, Cui D, Yee KL, Ballard J, Cabalu T, and Hochman J (2013) Drug-drug interaction studies: regulatory guidance and an industry perspective. AAPS J 15:629-645

Quintás-Cardama A, Vaddi K, Liu P, Manshouri T, Li J, Scherle PA, Caulder E, Wen X, Li Y, Waeltz P, et al. (2010) Preclinical characterization of the selective JAK1/2 inhibito INCB018424: therapeutic implications for the treatment of myeloproliferative neoplasms. Blood 115:3109-3117.

Ramsden D, Zhou J, and Tweedie DJ (2015) Determination of a degradation constant for CYP3A4 by direct suppression of mRNA in a novel human hepatocyte model, hepatoPac. Drug Metab Dispos 43:1307-1315.

Richez C, Truchetet ME, Kostine M, Schaeverbeke T, and Bannwarth B (2017) Efficacy of baricitinib in the treatment of rheumatoid arthritis. Expert Opin Pharmacother 18:1399-1407.

Rubin K, Janefeldt A, Andersson L, Berke Z, Grime K, and Andersson TB (2015) HepaRG cells as human-relevant in vitro model to study the effects of inflammatory stimuli on cytochrome P450 isoenzymes. Drug Metab Dispos 43:119-125.

Rudolph J, Heine A, Quast T, Kolanus W, Trebicka J, Brossart P, and Wolf D (2016) The JAK inhibitor ruxolitinib impairs dendritic cell migration via off-target inhibition of ROCK. Leukemia 30:2119-2123.

Schmitt C, Kuhn B, Zhang X, Kivitz AJ, and Grange S (2011) Disease-drug-drug interaction involving tocilizumab and simvastatin in patients with rheumatoid arthritis. Clin Pharmacol Ther 89:735-740.

Schönberg K, Rudolph J, Vonnahme M, Parampalli Yajnanarayana S, Cornez I, Hejazi M, Manser AR, Uhrberg M, Verbeek W, Koschmieder S, et al. (2015) JAK inhibition impairs NK cell function in myeloproliferative neoplasms. Cancer Res 75:2187-2199.

Shi JG, Chen X, Emm T, Scherle PA, McGee RF, Lo Y, Landman RR, McKeever EG, Jr, Punwani NG, Williams WV, et al. (2012) The effect of CYP3A4 inhibition or induction on the pharmacokinetics and pharmacodynamics of orally administered ruxolitinib (INCB018424 phosphate) in healthy volunteers. J Clin Pharmacol 52:809-818.

Shi JG, Fraczkiewicz G, Williams WV, and Yeleswaram S (2015) Predicting drug-drug interactions involving multiple mechanisms using physiologically based pharmacokinetic modeling: a case study with ruxolitinib. Clin Pharmacol Ther 97:177-185.

Sollazzo D, Forte D, Polverelli N, Perricone M, Romano M, Luatti S, Vianelli N, Cavo M, Palandri F, and Catani L (2016) Circulating calreticulin is increased in myelofibrosis: correlation with interleukin-6 plasma levels, bone marrow fibrosis, and splenomegaly. Mediators Inflamm 2016: 5860657.

Tabarroki A, Lindner DJ, Visconte V, Zhang L, Rogers HJ, Parker Y, Duong HK, Lichtin A, Kalaycio ME, Sekeres MA, et al. (2014) Ruxolitinib leads to improvement of pulmonary hypertension in patients with myelofibrosis. Leukemia 28:1486-1493.

Vyas D, O’Dell KM, Bandy JL, and Boyce EG (2013) Tofacitinib: the First Janus Kinase (JAK) inhibitor for the treatment of rheumatoid arthritis. Ann Pharmacother 47:1524-1531.

Weber A, Wasiliew P, and Kracht M (2010) Interleukin-1 (IL-1) pathway. Sci Signal 3:cm1

Yang Q, Doshi U, Li N, and Li AP (2012) Effects of culture duration on gene expression of P450 isoforms, uptake and efflux transporters in primary hepatocytes cultured in the absence and presence of interleukin-6: implications for experimental design for the evaluation of downregulatory effects of biotherapeutics. Curr Drug Metab 13:938-946.

Zhang D, Sun M, Samols D, and Kushner I (1996) STAT3 participates in transcriptional activation of the C-reactive protein gene by interleukin-6. J Biol Chem 271:9503-9509.

Zhou T, Georgeon S, Moser R, Moore DJ, Caflisch A, and Hantschel O (2014) Specificity and mechanism-of-action of the JAK2 tyrosine kinase inhibitors ruxolitinib and SAR302503 (TG101348). Leukemia 28:404-407.

Zhuang Y, de Vries DE, Xu Z, Marciniak SJ, Jr, Chen D, Leon F, Davis HM, and Zhou H (2015) Evaluation of disease-mediated therapeutic protein-drug interactions between an anti-interleukin6 monoclonal antibody (sirukumab) and cytochrome P450 activities in a phase 1 study in patients with rheumatoid arthritis using a cocktail approach. J Clin Pharmacol 55:1386-1394.

Address correspondence to: Dr. Olivier Fardel, Institut de Recherches en Santé, Environnement et Travail (IRSET), UMR INSERM U1085, Faculté de Pharmacie, Université de Rennes 1, 2 Avenue du Pr Léon Bernard, 34043 Rennes, France. E-mail: olivier.fardel@univ-rennes1.fr 